\section{Kidney \\ Blood Pressure Research}

\title{
Early Peritonitis is an Independent Risk Factor for Mortality in Elderly Peritoneal Dialysis Patients
}

\author{
Zhi Wang Linsen Jiang Sheng Feng Lei Yang Shan Jiang Zhoubing Zhan \\ Kai Song Huaying Shen
}

Department of Nephrology, Second Affiliated Hospital of Soochow University, Suzhou, China

\section{Key Words}

Early peritonitis • Elderly peritoneal dialysis patients • Mortality

\begin{abstract}
Background/Aims: The impact of early peritonitis on the outcome of elderly peritoneal dialysis (PD) patients has not been studied. We aimed to research the influence of early peritonitis on patient outcomes in elderly PD patients. Methods: This study involved elderly PD patients(age 265) who underwent PD between Jan 1, 2004 and Jul 31, 2013. Patient characteristics were collected in our database. Early peritonitis was defined as peritonitis within 6 months after the initiation of PD. Patient survival and technique were compared among thenon-peritonitis, early peritonitis and late peritonitis groups using Cox regression analysis. Results: There were 155 subjects involved in this study. The patients were divided among a non-peritonitis group $(n=78)$, early peritonitis group $(n=32)$ and late peritonitis group $(n=45)$. The organisms causing first peritonitis in the two groups did not differ significantly. After adjustment for age, diabetes, serum albumin and residual renal function, multivariable Cox regression model revealed that compared with the early peritonitis group, both the non-peritonitis group (HR 0.57, RI 0.32$0.99, p=0.046)$ and the late peritonitis group(HR 0.37, RI 0.16-0.75, $p=0.004)$ exhibited a lower patient mortality rate. Conclusions: Early peritonitis is an independent risk factor for mortality in elderly peritoneal dialysis patients.
\end{abstract}

Copyright (C) 2015 S. Karger AG, Basel

\section{Introduction}

The elderly population diagnosed with end-stage renal disease is growing rapidly in China. Because of its hemodynamic stability, home-based treatment options and better protection of residual renal function, numerous elderly patients choose peritoneal dialysis (PD) to treat renal failure [1,2]. Numerous studies demonstrate that older age, poor nutrition, comorbidities, and peritonitis are risk factors for mortality in elderly PD patients $[3,4]$. 


\section{Kidney \\ Blood Pressure Research}

Kidney Blood Press Res 2015;40:298-305

\begin{tabular}{l|l}
\hline DOI: $10.1159 / 000368505$ & C 2015 S. Karger AG, Basel
\end{tabular}

Published online: May 29, 2015

www.karger.com/kbr

Although previous studies have demonstrated similar risks of peritonitis in elderly and younger patients, the risk of peritonitis in elderly PD patients has been a particular concern [5]. Numerous studies have demonstrated that peritonitis is an independent risk factor for poor outcomes in PD patients [6-8]. However, several studies reported no influence of peritonitis on mortality in PD patients $[9,10]$.

Furthermore, several studies have already reported that early peritonitis is associated with mortality and technique failure in PD patients [11-13]. To date, this phenomenon has not been observed in elderly PD patients. We conducted this research with the following goals: (1) to examine whether peritonitis affects mortality in elderly PD patients and (2) to research the influence of early peritonitis on the outcome of elderly PD patients.

\section{Materials and Methods}

\section{Patients}

This was a retrospective study of all patients $\geq 65$ years of age who started PD between January 1 , 2004 and July 31, 2013 in our unit. All patient outcomes were followed through July 30, 2014. All patients had double-cuff silastic PD catheters placed using a sterile surgical technique. Patient demographics, ESRD aetiology and PD duration were obtained from charts and from a computerised database in our unit. Transfer to hemodialysis and death were defined as endpoints. Death during PD or within one month after conversion to HD was classified as PD-related mortality. Clinical outcomes were specified for mortality and technical failure. Patients who transferred to HD were censored from the patient survival analysis, and death was censored for technique failure. The exclusion criteria were as follows: (1) PD duration of less than 3 months; (2) inadequate follow-up clinical information; and (3) a prior history of hemodialysis.

\section{Diagnosis of early onset peritonitis}

Peritonitis was diagnosed according to the standard criteria: The diagnosis of peritonitis complicating PD was based on at least two of the following criteria: abdominal pain or cloudy PD effluent, leukocytosis in peritoneal fluid effluent (white cell count at least $100 / \mathrm{mm} \mathrm{3}$ ), or positive Gram stain or culture of effluent [14]. Early onset peritonitis was defined as peritonitis within 6 months after the initiationof PD.

\section{Collection of Clinical Data}

The subject data, including age, gender, serum albumin(ALB), creatinine, serum calcium, phosphate, KT/V, and residual renal function, were recorded 1 to 3 months after PD initiation. We collected these data in the database at our centre. All peritonitis episodes were recorded, and for each peritonitis episode, the causative microorganism was recorded, if isolated.

\section{Statistical analysis}

Continuous variables are presented as the means $\pm \mathrm{SD}$, and categorical variables are expressed as percentages unless otherwise stated. For comparisons of continuous variables between two groups,Student's t-test was used. The Kolmogorov-Smirnov test was used to analyse the normality of continuous data. The relationships between 2 or more groups of data were analysed using Pearson chi-squared test. Survival curves were generated by the Kaplan-Meier method and compared by the log-rank test. Factors predictive of patient and technique survival were identified with Cox regression. Factors with $p<0.10$ on univariate analysis were entered into the multivariable Cox regression model. A backward elimination procedure using $p>0.05$ was performed to identify independent predictors for patient and technique survival. All computations were performed using SPSS 17.0 for Windows (SPSS Inc., Chicago, IL, USA), and p $<0.05$ was considered statistically significant.

\section{Ethics statement}

The study protocol was approved by the Ethics Committee of the Second Affiliated Hospital of Soochow University. Due to the retrospective nature of the study, informed written consent was waived, and informed consent was therefore not obtained. 


\section{Kidney \\ Blood Pressure Research}

\section{Kidney Blood Press Res 2015;40:298-305}

\begin{tabular}{l|l}
\hline DOI: $10.1159 / 000368505$ & (c) 2015 S. Karger AG, Basel
\end{tabular}

Published online: May 29, 2015

www.karger.com/kbr

in Elderly PD Patients

Table 1. Comparison of baseline characteristics in non-peritonitis, early peritonitis and late peritonitis patients

\begin{tabular}{lccc}
\hline Clinical parameters & $\begin{array}{c}\text { Non-peritonitis } \\
(\mathrm{n}=78)\end{array}$ & $\begin{array}{c}\text { Early peritonitis } \\
(\mathrm{n}=32)\end{array}$ & $\begin{array}{c}\text { Late peritonitis } \\
(\mathrm{n}=45)\end{array}$ \\
\hline Age(years) & $73.6 \pm 5.7$ & $75.4 \pm 7.32$ & $72.6 \pm 5.8^{*}$ \\
Gender(male/female) & $46 / 32$ & $14 / 18$ & $22 / 23$ \\
BMI (kg/m2) & $22.4 \pm 2.8$ & $20.5 \pm 3.0^{\#}$ & $21.8 \pm 2.8$ \\
Diabetes n(\%) & $35(44.9)$ & $9(28.1)$ & $13(28.9)$ \\
Etiology of ESRD n(\%) & & & \\
Primary glomerulonephritis & $39(50.0)$ & $14(43.8)$ & $20(44.4)$ \\
Diabetic nephropathy & $24(30.8)$ & $4(12.5)$ & $8(17.8)$ \\
Hypertensive nephropathy & $7(9.0)$ & $10(31.3)$ & $11(24.4)$ \\
Other & $8(10.3)$ & $4(12.5)$ & $6(13.3)$ \\
Serum albumin(g/dl) & $2.9 \pm 0.5$ & $2.5 \pm 0.6^{\&}$ & $2.8 \pm 0.6 @$ \\
Hemoglobin(g/dl) & $10.7 \pm 2.0$ & $10.2 \pm 2.4$ & $10.3 \pm 2.4$ \\
Phosphorus (mmol/L) & $1.40 \pm 0.35$ & $1.31 \pm 0.38$ & $1.4 \pm 0.37$ \\
Calcium (mmol/L) & $2.11 \pm 0.26$ & $2.07 \pm 0.25$ & $2.09 \pm 0.29$ \\
CRP & $6(5,12)$ & $6(5,12)$ & $6(5,8)$ \\
KT/V urea & $1.75 \pm 0.48$ & $1.83 \pm 0.77$ & $1.68 \pm 0.43$ \\
RRF(ml/min/1.73m2) & $3.80 \pm 3.09$ & $2.73 \pm 2.66^{\#}$ & $3.16 \pm 2.86^{\&}$ \\
D/P Creatinine at 4h & $0.64 \pm 0.13$ & $0.73 \pm 0.12^{\#}$ & $0.68 \pm 0.15$ \\
\hline BMI, body mass index; CRP, C-reactive protein; RRF, residual renal function; \\
\#, compare to non-peritonitis group,p<0.05; \&, compare to non-peritonitis \\
group,p<0.01; *, compare to early peritonitis group, p<0.05; @, compare to early \\
peritonitis group, p<0.01 \\
\hline
\end{tabular}

\section{Results}

During the study period, 180 subjects were referred to the dialysis centre. Eleven subjects died within 3 months after the initiation of PD, but none of these patients suffered early peritonitis. Five patients were transferred out of the unit, and three patients exhibited renal function recovery. Six patients had a prior hemodialysis history. No patients underwent renal transplantation. Thus, only 155 patients were eligible for the final analysis. According to the diagnosis criteria of peritonitis and early peritonitis, 155 subjects were divided into nonperitonitis group $(n=78)$, early peritonitis group $(n=32)$ and late peritonitis group $(n=45)$.

\section{Patient characteristics}

Among the study subjects, $47.1 \%$ were female $(n=73)$, and $52.9 \%$ were male $(n=82)$. The mean age of the subjects was $73.7 \pm 6.1$ years. The mean duration of treatment was 24.5 \pm 20.3 months (range 3-125 months). There were 43 patients under daytime ambulatory peritoneal dialysis (DAPD), whereas the remaining 112 patients underwent continuous ambulatory peritoneal dialysis (CAPD). No patients underwent automated peritoneal dialysis (APD) due to a medical insurance policy. All patients used a double-bag Y-set system produced by Baxter. All patients were given 1.5\% and/or 2.5\% Dextrose dialysate (Dianeal, Baxter) for PD.No patient were given biocompatible dialysate because of unavailbility. Additional demographic characteristics, ESRD aetiology and the laboratory characteristics of the patients are presented in Table 1.

There were 62 patients undergoing assisted PD, aided either by a family member $(n=54)$ or nurse $(n=8)$. The remaining 93 patients performed PD by themselves. The number of assisted PD patients did not differ significantly among the three groups. There were 3 nurseassisted patients and 13 family member-assisted patients diagnosed with early peritonitis. The number of early peritonitis patients did not differ between the assisted PD group and the self-care PD group. 


\section{Kidney \\ Blood Pressure Research}

Kidney Blood Press Res 2015;40:298-305

\begin{tabular}{l|l}
\hline DOI: $10.1159 / 000368505$ & C 2015 S. Karger AG, Basel
\end{tabular}

Published online: May 29, 2015

www.karger.com/kbr

Wang/Jiang/Feng/Yang/Jiang/Zhan/Song/Shen: Impact of Early Peritonitis on Mortality in Elderly PD Patients

In this study,

the observation

period started with

initiation of PD. In

this study, there

were only 4 patients

did not start PD

immediately after PD

catheter insertion.

These patients did not have peritonitis before PD initiation. Furthermore, these four patients did not die or transfer to

Table 2. Causes of death and technique failure in early peritonitis and non- early peritonitis patients

\begin{tabular}{lccc}
\hline Clinical outcome & $\begin{array}{c}\text { Non- } \\
\text { peritonitis } \\
(\mathrm{n}=78)\end{array}$ & $\begin{array}{c}\text { early } \\
\text { peritonitis } \\
(\mathrm{n}=32)\end{array}$ & $\begin{array}{c}\text { Late } \\
\text { peritonitis } \\
(\mathrm{n}=45)\end{array}$ \\
\hline Death & 31 & 21 & 18 \\
$\quad$ Cardiovascular events & 14 & 10 & 9 \\
$\quad$ Infection & 7 & 5 & 4 \\
$\quad$ Cachexia & 4 & 2 & 2 \\
$\quad$ Other & 6 & 4 & 3 \\
Technique failure & 4 & 3 & 5 \\
recurrent peritonitis & 2 & 2 & 2 \\
refractory heart failure & 1 & 1 & 1 \\
ultrafiltration failure & 1 & 0 & 1 \\
tunnel infection & 0 & 0 & 1 \\
\hline
\end{tabular}

hemodialysis before PD initiation.

During the observation period of almost 10 years, teaching or training procedure for PD patients had no major changes. Besides, during this period, we use mopirocin to smear over nasal cavity in patients whose nasal cultured with gram positive coccus.

There were two patients who diagnosed with Microscopic polyangiitis were taking azathioprine and low dosage prednisone $(10-15 \mathrm{mg} / \mathrm{d})$. These patients were included in this study, and neither of them had peritonitis.

Organisms causing peritonitis in the early and late peritonitis groups

One hundred five episodes of peritonitis occurred in 77 patients, and the peritonitis rate was 1 per 40.5 patient-months. The mean peritonitis-free period was $22 \pm 15$ months. Thirtytwo $(20.6 \%)$ patients diagnosed with early peritonitis. Peritonitis occurred more frequently in the early peritonitis group (1 per 23.7 patient-months) than in the late peritonitis group (1 per 36.4 patient-months). Eleven patients who occurred peritontis were caused by exit infection( $n=9)$ or tunnel infection(n=2). The episodes of exit and tunnel infection did not differ significantly between the early and late peritonitis groups.

In the early peritonitis group, the culture results of the first peritonitis episode revealedgram-positive organisms $(n=19)$, gram-negative organisms $(n=9)$, fungi $(n=1)$ and culture-negative results $(n=3)$. In the late peritonitis group, the culture results of the first peritonitis episode includedgram-positive organisms $(n=22)$, gram-negative organisms $(n=12)$ and culture-negative results $(n=5)$. The organisms causing the first peritonitis episode did not differ between the two groups.

\section{Causes of death and technique failure}

During the follow-up period, 70 subjects died with a mean observation time of $22.9 \pm$ 19.0 months. Thirty-three patients died of cardiovascular events, including cardiac arrest $(n=7)$, acute myocardial infarction $(n=6)$, cardiac arrhythmias $(n=5)$, heart failure $(n=9)$, and stroke $(n=6)$. Seventeen subjects died of infection, including 10 deaths due to pneumonia, 4 due to peritonitis and other 3 due to sepsis.The causes of sepsis include acute gastroenteritis $(n=2)$ and infective diabetic foot $(n=1)$.The remaining 20 subjects died of cachexia $(n=8)$, gastrointestinal bleeding $(n=3)$, malignancy $(n=1)$ and unknown causes $(n=8)$. Twelve subjects were transferred to hemodialysisdue to recurrent peritonitis $(n=6)$, refractory heart failure ( $n=3)$, ultrafiltration failure $(n=2)$ and tunnel infection $(n=1)$.The causes of death and technique failure in the non-peritonitis, early peritonitis and late peritonitis patients are presented in Table 2 . 


\section{Kidney \\ Blood Pressure \\ Research}

Kidney Blood Press Res 2015;40:298-305

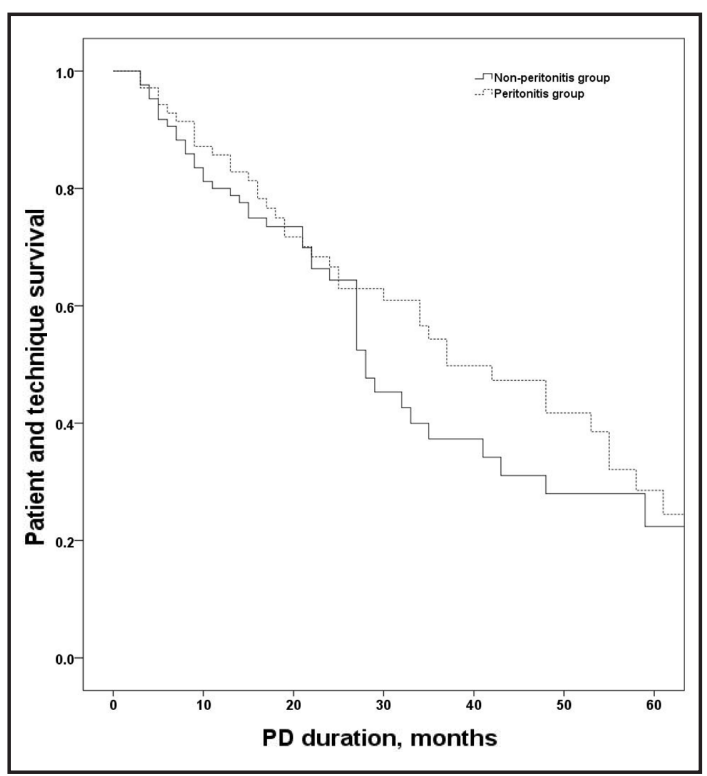

Fig. 1. Comparision of patient and technique survival in patients with peritonitis and without peritonitis (Log rank test $=0.575, \mathrm{p}=0.448$ ).

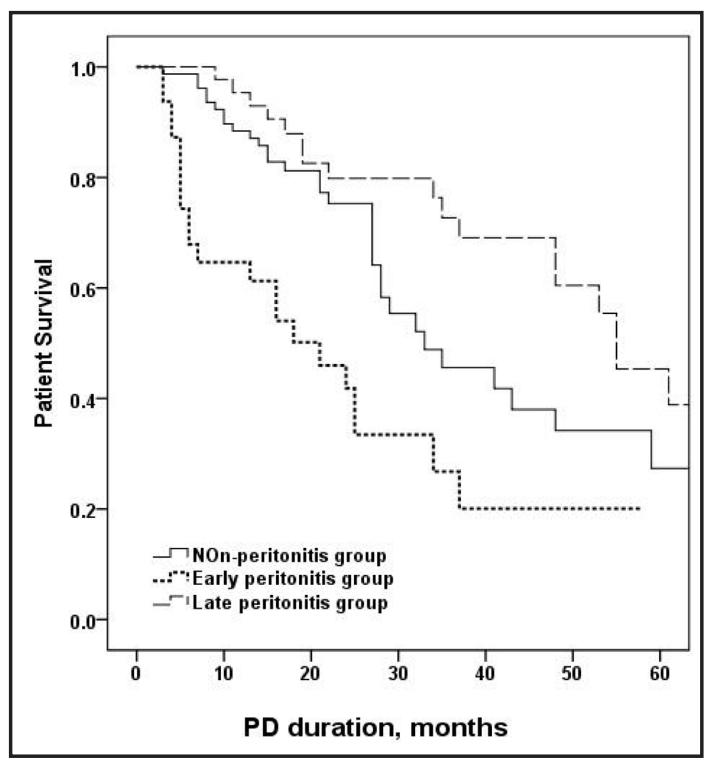

Fig. 3. Patient mortality in early peritonitis and Non- early peritonitis groups(Log rank test=18.19, $\mathrm{p}<0.001$ ).

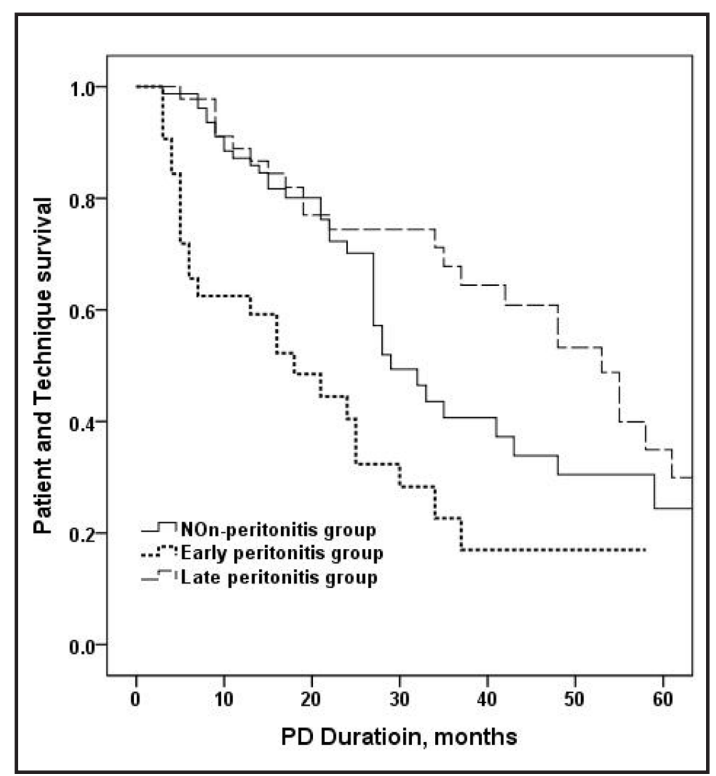

Fig. 2. Comparision of patient and technique survival in early peritonitis and Non- early peritonitis groups(Log rank test $=16.83, \mathrm{p}<0.001)$.

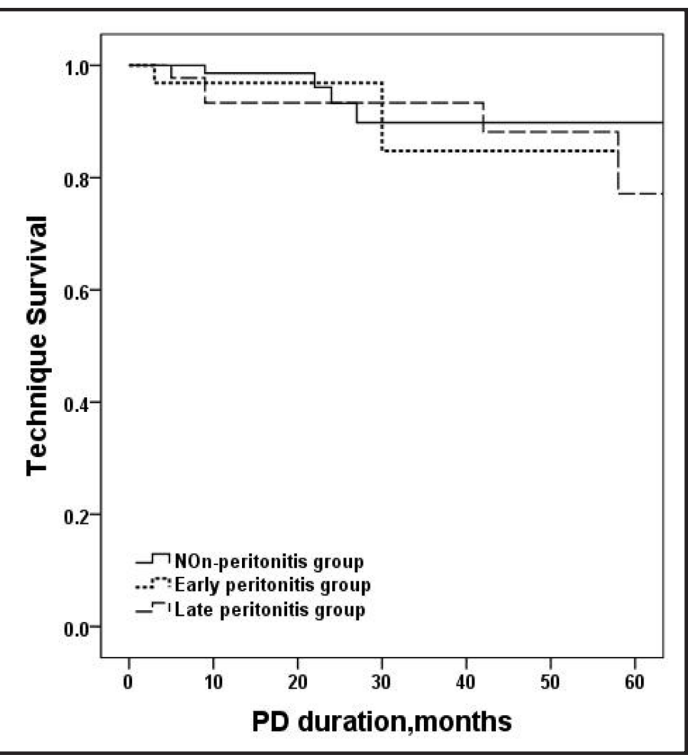

Fig. 4. Technique survival in early peritonitis and Non-early peritonitis groups(Log rank test $=0.158$, $\mathrm{p}=0.691$ ).

Comparison of outcomes in the non-peritonitis, early peritonitis and late peritonitis groups

Patient outcomes did not differ between patients with and without peritonitis (Log rank test $=0.575, p=0.448$, Figure 1 ). However, the total survival in early peritonitis group was lower than in non-peritonitis and late peritonitis groups ( $\mathrm{p}<0.001$, Figure 2 ). In a univariate Cox regression model, using the early peritonitis group as a reference, both the non-peritonitis group (HR 0.40, RI 0. 23-0.71, p=0.001) and late peritonitis group (HR 0.26, RI 0.14-0.50, $\mathrm{p}<0.001$ ) exhibited decreased risk of mortality (Figure 3). However, there was no significant difference in technique failure among the three groups (Figure 4). 


\section{Kidney \\ Blood Pressure Research}

Table 3. Predictors of mortality and technique failure in PD patients

\begin{tabular}{|c|c|c|c|c|c|c|}
\hline \multirow{2}{*}{ Variables } & \multicolumn{3}{|c|}{ univariate Cox regression analysis } & \multicolumn{3}{|c|}{ multivariate Cox regression analysis } \\
\hline & $\mathrm{B}$ & $\mathrm{HR}(95 \% \mathrm{CI})$ & $\mathrm{p}$-value & $\mathrm{B}$ & $\mathrm{HR}(95 \% \mathrm{CI})$ & $\mathrm{p}$-value \\
\hline \multicolumn{7}{|c|}{ Predictors of mortality and technique failure in elderly PD patients } \\
\hline Age(per 10-year increase) & 0.834 & $2.30(1.59-3.33)$ & $<0.001$ & 0.573 & $1.77(1.19-2.65)$ & 0.005 \\
\hline Albumin(per $1 \mathrm{~g} / \mathrm{dl}$ decrease) & 0.933 & $2.54(1.69-3.83)$ & $<0.001$ & 0.753 & $2.08(1.32-3.28)$ & 0.002 \\
\hline $\mathrm{RRF}($ per $1 \mathrm{ml} / \mathrm{min} * 1.73 \mathrm{~m} 2$ decrease) & 0.162 & $1.18(1.06-1.30)$ & 0.002 & 0.116 & $1.13(1.01-1.26)$ & 0.026 \\
\hline $\mathrm{D} / \mathrm{P}$ Creatinine at $4 \mathrm{~h}$ & 0.308 & $1.36(1.01-1.83)$ & 0.040 & - & - & - \\
\hline Peritonitis group* & & & $<0.001$ & & & 0.051 \\
\hline Non-peritonitis group & -0.876 & $0.42(0.25-0.71)$ & 0.001 & -0.514 & $0.60(0.34-1.04)$ & 0.070 \\
\hline Late peritonitis group & -1.139 & $0.32(0.18-0.58)$ & $<0.001$ & -0.779 & $0.46(0.24-0.87)$ & 0.017 \\
\hline \multicolumn{7}{|c|}{ Predictors of technique failure in elderly PD patients } \\
\hline Albumin(per 1g/dl decrease) & 1.136 & $3.12(1.06-9.14)$ & 0.039 & 1.251 & $3.50(1.09-9.96)$ & 0.025 \\
\hline Diabetes mellitus & 0.971 & $2.64(1.03-6.23)$ & 0.017 & 1.019 & $2.77(1.06-6.51)$ & 0.036 \\
\hline \multicolumn{7}{|c|}{ Predictors of mortality in elderly PD patients } \\
\hline Age(per 10-year increase) & 0.924 & $2.52(1.70-3.74)$ & $<0.001$ & 0.638 & $1.89(1.23-2.90)$ & 0.004 \\
\hline Albumin(per 1g/dl decrease) & 0.898 & $2.46(1.58-3.82)$ & $<0.001$ & 0.648 & $1.91(1.16-3.14)$ & 0.010 \\
\hline $\mathrm{D} / \mathrm{P}$ Creatinine at $4 \mathrm{~h}$ & 0.278 & $1.32(0.97-1.80)$ & 0.076 & - & - & - \\
\hline $\mathrm{RRF}\left(\right.$ per $1 \mathrm{ml} / \mathrm{min}^{*} 1.73 \mathrm{~m} 2$ decrease) & 0.168 & $1.18(1.06-1.32)$ & 0.003 & 0.133 & $1.14(1.02-1.29)$ & 0.028 \\
\hline Peritonitis group* & & & $<0.001$ & & & 0.021 \\
\hline Non-peritonitis group & -0.908 & $0.40(0.23-0.71)$ & 0.001 & -0.551 & $0.57(0.32-0.99)$ & 0.046 \\
\hline Late peritonitis group & -1.304 & $0.26(0.14-0.50)$ & $<0.001$ & -0.989 & $0.37(0.16-0.75)$ & 0.004 \\
\hline
\end{tabular}

As presented in Table 3, age, serum albumin and RRF were correlated with mortality and total survival in PD patients by univariate Cox regression model. In a multivariate Cox regression model (Table 3 ), using the early peritonitis group as a reference, the mortality hazard ratios were 0.57 (RI 0.32-0.99, $\mathrm{p}=0.046$ ) in the non-peritonitis group and 0.37 (RI $0.16-0.75, \mathrm{p}=0.004$ ) in the late peritonitis group.

\section{Discussion}

In this study, we determined that early peritonitis is an independent risk factor for mortality in elderly PD patients. Furthermore, early peritonitis has no impact on technique survival in this population.

The definition of early peritonitis remains controversial. In a recently published study of 1677 incident peritoneal dialysis patients in America, three-fourths of patients exhibited a first peritonitis episode within the first 6 months of peritoneal dialysis treatment [15]. The BRAZPD study revealed that the median time to the first episode of peritonitis in elderly PD patients was 6 months [16]. In our study, nearly half of the early peritonitis episodes occurred during the first 6 months after PD initiation. Based on these observations, it is convincible to use 6 months as the cut-off point to define early peritonitis.

In this study, we determined that peritonitis is not an independent risk factor for poor outcomes in elderly PD patients. This result is consistent with research conducted by Isla RA et al [9]. Previous studies identified peritonitis as an independent risk factor for patients and technique survival in PD patients $[6,7,13]$. The impact of peritonitis changed largely due to the decrease in the peritonitis rate through the use of the double-bag or Y-set [17]. Furthermore, of the number of effective peritonitis treatments increased after the widespread application of the ISPD guidelines $[18,19]$.

In this research study, we determined that early peritonitis is an independent risk factor for mortality in elderly PD patients. This result is consistent with the study conducted by Hsieh YP et al [11]. There are several reasons for this phenomenon. First, patients with early peritonitis exhibited an increased peritonitis rate. Frequent peritonitis is a risk factor for mortality in PD patients. Second, patients with early peritonitis may be in poor health. In this study, patients in the early peritonitis group were older and exhibited a lower ALB 


\section{Kidney \\ Blood Pressure Research}

Kidney Blood Press Res 2015;40:298-305

\begin{tabular}{l|l}
\hline DOI: 10.1159/000368505 & (C) 2015 S. Karger AG, Basel
\end{tabular}

Published online: May 29, 2015

www.karger.com/kbr

level, either of which can negatively impact patient outcomes. Besides, lower ALB level and proteinuria may cause decline in residual renal function, which can worsen the prognosis of PD patients [20].

Finally, early peritonitis has no impact on technique survival in elderly patients, possibly due to the lower rate of lower technique failure in elderly PD patients than in younger patients [21]. It is also possible that a relative small patient population may have affected the results.

There are several limitations in our study. First, this study was conducted in a single centre with a relatively small number of subjects. Second, due to the respective nature of this study, some potentially important characteristics such as the subjective global assessment score and the co-morbidity index score were not recorded.

\section{Conclusion}

Our study demonstrates that early peritonitis has a negative influence on mortality in elderly PD patients. To confirm this relationship and clarify the underlying mechanisms, a prospective study should be conducted.

\section{Disclosure Statement}

Zhi Wangand Linsen Jiangcontribute equally to this article.We certify that all authors have no financial or other conflict of interests in connection with the submitted article.

\section{Reference}

1 Harris SA, Lamping DL, Brown EA, Constantinovici N: Clinical outcomes and quality of life in elderly patients on peritoneal dialysis versus hemodialysis. Perit Dial Int 2002;22:463-470.

2 Cameron JI, Whiteside C, Katz J, Devins GM: Differences in quality of life across renal replacement therapies: A meta-analytic comparison. Am J Kidney Dis 2000;35:629-637.

3 Genestier S, Meyer N, Chantrel F, Alenabi F, Brignon P, Maaz M, Muller S, Faller B: Prognostic survival factors in elderly renal failure patients treated with peritoneal dialysis: A nine-year retrospective study. Perit Dial Int 2010;30:218-226.

4 Hung CC, Chang CT, Lee CC, Chen KH, Yu CC, Wu CH, Huang JY, Wu MS, Yang CW: Prognostic predictors of technique and patient survival in elderly southeast asian patients undergoing continuous ambulatory peritoneal dialysis. Int J Clin Pract 2009;63:254-260.

5 Brown EA: Should older patients be offered peritoneal dialysis? Perit Dial Int 2008;28:444-448.

6 Kavanagh D, Prescott GJ, Mactier RA: Peritoneal dialysis-associated peritonitis in scotland (1999-2002). Nephrol Dial Transplant 2004;19:2584-2591.

7 Mizuno M, Ito Y, Tanaka A, Suzuki Y, Hiramatsu H, Watanabe M, Tsuruta Y, Matsuoka T, Ito I, Tamai H, Kasuga H, Shimizu H, Kurata H, Inaguma D, Hiramatsu T, Horie M, Naruse T, Maruyama S, Imai E, Yuzawa Y, Matsuo S: Peritonitis is still an important factor for withdrawal from peritoneal dialysis therapy in the tokai area of japan. Clin Exp Nephrol 2011;15:727-737.

8 Davenport A: Peritonitis remains the major clinical complication of peritoneal dialysis: The london, uk, peritonitis audit 2002-2003. Perit Dial Int 2009;29:297-302.

9 Isla RA, Mapiye D, Swanepoel CR, Rozumyk N, Hubahib JE, Okpechi IG: Continuous ambulatory peritoneal dialysis in limpopo province, south africa: Predictors of patient and technique survival. Perit Dial Int 2014;34:518-525.

10 Hsieh YP, Chang CC, Wen YK, Chiu PF, Yang Y: Predictors of peritonitis and the impact of peritonitis on clinical outcomes of continuous ambulatory peritoneal dialysis patients in taiwan--10 years' experience in a single center. Perit Dial Int 2014;34:85-94. 


\section{Kidney \\ Blood Pressure Research}

\section{Kidney Blood Press Res 2015;40:298-305}

DOI: $10.1159 / 000368505$

Published online: May 29, 2015

(C) 2015 S. Karger AG, Basel

www.karger.com/kbr

11 Hsieh YP, Wang SC, Chang CC, Wen YK, Chiu PF, Yang Y: The negative impact of early peritonitis on continuous ambulatory peritoneal dialysis patients. Perit Dial Int 2014;34:627-635.

12 Harel Z, Wald R, Bell C, Bargman JM: Outcome of patients who develop early-onset peritonitis. Adv Perit Dial 2006;22:46-49.

13 Fourtounas C, Savidaki E, Dousdabanis P, Hardalias A, Kalliakmani P, Papachristou E, Drakopoulos A, Goumenos DS, Vlachojannis JG: Peritonitis during the first year after commencement of peritoneal dialysis has an impact on technique survival and patient morbidity. Adv Perit Dial 2006;22:50-54.

14 Keane WF, Alexander SR, Bailie GR, Boeschoten E, Gokal R, Golper TA, Holmes CJ, Huang CC, Kawaguchi Y, Piraino B, Riella M, Schaefer F, Vas S: Peritoneal dialysis-related peritonitis treatment recommendations: 1996 update. Perit Dial Int 1996;16:557-573.

15 Pulliam J, Li NC, Maddux F, Hakim R, Finkelstein FO, Lacson E, Jr: First-year outcomes of incident peritoneal dialysis patients in the united states. Am J Kidney Dis 2014;64:761-769.

16 Martin LC, Caramori JC, Fernandes N, Divino-Filho JC, Pecoits-Filho R, Barretti P: Geographic and educational factors and risk of the first peritonitis episode in brazilian peritoneal dialysis study (brazpd) patients. Clin J Am Soc Nephrol 2011;6:1944-1951.

17 Daly C, Cody JD, Khan I, Rabindranath KS, Vale L, Wallace SA: Double bag or y-set versus standard transfer systems for continuous ambulatory peritoneal dialysis in end-stage kidney disease. Cochrane Database Syst Rev 2014;8:CD003078.

18 Boeschoten EW, Ter Wee PM, Divino J: Peritoneal dialysis-related infections recommendations 2005--an important tool for quality improvement. Nephrol Dial Transplant 2006;21 Suppl 2:II31-33.

19 Li PK, Szeto CC, Piraino B, Bernardini J, Figueiredo AE, Gupta A, Johnson DW, Kuijper EJ, Lye WC, Salzer W, Schaefer F, Struijk DG: Peritoneal dialysis-related infections recommendations: 2010 update. Perit Dial Int 2010;30:393-423.

20 Kang SH, Cho KH, Park JW, Yoon KW, Do JY. Proteinuria as a risk factor for decline in residual renal function in non-diabetic peritoneal dialysis patients. Kidney Blood Press Res. 2013;37:199-210.

21 Lim WH, Dogra GK, McDonald SP, Brown FG, Johnson DW: Compared with younger peritoneal dialysis patients, elderly patients have similar peritonitis-free survival and lower risk of technique failure, but higher risk of peritonitis-related mortality. Perit Dial Int 2011;31:663-671. 